\title{
Meta
}

Journal des traducteurs

Translators' Journal

\section{Lombez, C. (2003) : Transactions secrètes. Philippe Jaccottet, poète et traducteur de Rilke et Hölderlin, Arras, Artois Presses Université, 182 p.}

\section{Roger Goffin}

Volume 49, numéro 4, décembre 2004

URI : https://id.erudit.org/iderudit/009803ar

DOI : https://doi.org/10.7202/009803ar

Aller au sommaire du numéro

Éditeur(s)

Les Presses de l'Université de Montréal

ISSN

0026-0452 (imprimé)

1492-1421 (numérique)

Découvrir la revue

Citer ce compte rendu

Goffin, R. (2004). Compte rendu de [LOMBEZ, C. (2003) : Transactions secrètes. Philippe Jaccottet, poète et traducteur de Rilke et Hölderlin, Arras, Artois Presses Université, 182 p.] Meta, 49(4), 958-959. https://doi.org/10.7202/009803ar d'utilisation que vous pouvez consulter en ligne.

https://apropos.erudit.org/fr/usagers/politique-dutilisation/ 


\section{NOTES}

1. Je trouve, ou imagine, une bonne dizaine de Hollandais, trois Anglais, deux Sud-Africains, un Tchèque, un Belge, une Finlandaise, un Hongrois, une Italienne, et quelques autres.

2. Malheureusement les illustrations y sont référencées de manière très imprécise: «Webster's 2nd ed.» (p. 50), «Webster New International Dictionary 2nd ed., 1950» (qui n'existe pas dans la bibliographie), «OED» (qui n'existe pas dans la bibliographie non plus) sans indication de l'édition (p. 54), «Webster's Third» (p. 56).

3. En gros, le sémasiologue va du signifiant au signifié, et reste donc dans le signe, alors que l'onomasiologue va du conceptuel, ou même du référentiel, au linguistique sauf à considérer que l'on part du signifié, ce qui semble bien difficile avant même l'identification d'un signe.

4. Seul Sinclair (p. 178) fait explicitement référence au glossaire du recueil.

\section{RÉFÉRENCES}

Cruse, D.A. (1986) : Lexical Semantics, Cambridge, Cambridge University Press.

Landau, S. (2001): Dictionaries, The Art and Craft of Lexicography, Cambridge, Cambridge University Press.

Svénsen, B. (1994): Practical Lexicography, Oxford, Oxford University Press.

Lombez, C. (2003): Transactions secrètes. Philippe Jaccottet, poète et traducteur de Rilke et Hölderlin, Arras, Artois Presses Université, 182 p.

Par quelle mystérieuse alchimie deux poètes allemands des siècles passés, d'une part, Friedrich Hölderlin (1770-1843), et, d'autre part, Rainer Maria Rilke (1875-1926), ont-ils pu marquer d'une empreinte indélébile l'écriture fictionnelle du poète vaudois contemporain Philippe Jaccottet? Réponse: par la traduction française de ces deux auteurs, que le Suisse a pratiqué tout au long de son propre parcours littéraire. L'impact des œuvres traduites sur ses créations personnelles est considérable; en effet, sa création plonge des racines profondes dans le «terreau intellectuel» qu'il a su mettre au jour dans les écrits, comme le formule l'auteure.

Christine Lombez, normalienne, agrégée et docteur, nous livre dans son ouvrage Transactions secrètes, (c'est le titre, mis au pluriel d'un recueil de textes de Jaccottet, paru en 1987), les résultats d'une étude très fouillée sur la nature complexe des échanges «secrets» qui s'opèrent entre l'œuvre créatrice du poète - traducteur suisse et ses traductions de Rilke et Hölderlin. De tout temps, les poètes ont entretenu un rapport privilégié avec la traduction: les liens qui existent entre les deux activités, sans avoir été pour autant à chaque fois formalisés, sont au cœur d'une même démarche.

L'auteure met en perspective l'étroite relation dialogique du poète créateur et des œuvres traduites et recherche les traces objectives laissées dans l'écriture poétique par les auteurs traduits. Elle met en lumière à la fois Jaccottet traducteur, ses conceptions de la traduction et la place que celle-ci occupe dans ses procédés créatifs.

Dans un chapitre liminaire très dense, l'auteure rappelle à grand renfort de citations, trop souvent de seconde main (via A. Berman), les controverses séculaires autour du littéralisme, des belles infidèles, et les apports de l'école allemande de traduction. À l'inverse des traductions «enjolivantes» et "ethnocentriques» à la française, l'école allemande fit jouer à la traduction, à travers le concept de Bildung un rôle fondamental dans la formation de la langue.

La traduction comme transformation et transposition créatrice a pour la langue un effet à la fois enrichissant et dynamisant. Leur thèse se résume comme suit: seule la traduction permet un recul suffisant par rapport à la «vision interne globale» de l'œuvre. Se prévalant d'un nouveau rapport qui s'institue entre l'homme et le langage, la traduction devient, comme plus tard chez Heidegger, partie intégrante de la réflexion philosophique. Cette école fonde l'hypothèse suivant laquelle traduire le réel en mots pose les mêmes problèmes que traduire d'une langue à l'autre. 
«Avant d'être» colporteur de poésie et «poète nautonier», l'écrivain suisse s'est profilé comme traducteur (activité purement alimentaire), notamment par une nouvelle version française La mort à Venise de T. Mann. En prêtant ainsi sa voix à d'autres, Jaccottet a réellement accédé à la parole poétique (p. 58), sa première traduction coïncidant avec Requiem son premier recueil, publié en 1947. Ses auteurs de prédilection ont été R. Musil, R.M. Rilke, F. Hölderlin et I. Bachmann, pour l'allemand; Le Tasse, Leopardi et Ungaretti pour l'italien; Gongora pour l'espagnol et Platon et Homère pour le grec. Jaccottet n'a pourtant jamais théorisé ni formalisé sa pratique si ce n'est dans les préfaces, postfaces ou notes occasionnelles. Pour lui, la traduction est une religion, c'est-à-dire une activité qui relie, qui met en contact des voix entre elles par delà la langue.

Dans le chapitre "Apprentissage de la poésie», C. Lombez montre que, dès l'adolescence, l'influence de Rilke est patente; le premier texte traduit remonte à 1949 et dans Transactions secrètes il regrette les insuffisances de la traduction française des Élégies de Duino dans la version de Armel Guern. Dans les années suivantes, cette influence reste diffuse (p.75) mais profonde, puis Jaccottet se détourne du raffinement rilkéen pour s'engager dans la voie d'un plus grand dépouillement. Il existe, écrit l'auteure, une réelle «innutrition» dans le domaine thématique et de l'écriture: proximité et motif de la pauvreté, valeur à la fois morale et poétique, insécurité linguistique, thème de la finitude et de la mort, même conception de la langue poétique.

La rencontre avec l'œuvre de F. Hölderlin apparaît avec la maturité intellectuelle. On a affaire ici à une véritable empathie, à un phénomène "l'imprégnation thématique».

Jaccottet partage avec Hölderlin une même fascination pour la Grèce antique, les mêmes interrogations sur la quête et l'absence de Dieu sur le divin et le sacré. Il a été amené au poète allemand par le biais des traductions que G. Roud publia dans les années 1940. Il faudra en effet attendre le $\mathrm{xx}^{\mathrm{e}}$ siècle pour découvrir en France l'écriture de Hölderlin dans sa traduction française, à travers plusieurs générations de poètes traducteurs tels que J. Tardieu, M. Deguy, P.-J. Jouve.

L'échange entre Jaccottet et Hölderlin fonctionne toujours dans les deux sens; «certains ouvrages du Suisse témoignent de ce que Hölderlin a pu offrir comme «incitations poétiques », mais aussi de ce que Jaccottet a lui-même apporté à l'écriture de Hölderlin dans sa version française», écrit justement l'auteure.

L'analyse comparative très minutieuse des deux traductions de la célèbre ode asclépiade Heidelberg (1800) permet de mesurer la créativité de Jaccottet, dont la traduction (1967) plus expressive et respectueuse du rythme de l'original, contraste avec celle de G. Bianquis (1943) plus scrupuleuse et plus universitaire. Dans le chapitre intitulé "De l'autre côté du miroir ", l'auteure passe au crible la version allemande de la poésie de Jaccottet établie avec bonheur par Friedhelm KEMP avec l'assistance personnelle de l'auteur.

Dirons-nous notre regret de n'avoir pas pu lire une synthèse plus rigoureusement établie, et qui eut, à son tour intégré les acquis des différents chapitres. On regrettera aussi l'absence trop fréquente de références complètes aux auteurs allemands (les pages ne sont pas reprises) ce qui empêche de retrouver (et de vérifier) tel ou tel passage cité.

L'apport le plus fécond de cette étude réside dans l'analyse subtile du phénomène de réception au sens d'accueil fait dans une langue donnée à l'héritage littéraire et culturel étranger, comme ici d'une époque antérieure, ainsi que le prolongement dans le milieu récepteur de cet apport, le cas échéant, complété et recréé.

Que conclure? Nous sommes en présence d'un livre qui, partant de l'hypothèse de la traduction généralisée, jette par des rapprochements significatifs et par l'analyse de «secrètes transactions » un éclairage inattendu sur les rapports intimes de la création poétique et de l'acte de traduction, en général et chez P. Jaccottet en particulier. 